\title{
ROADELS: DISCRETE INFORMATION OBJECTS FOR PRODUCTION PLANNING AND CONTROL OF ROAD CONSTRUCTION
}

\author{
SUBMITTED: March 2019 \\ REVISED: March 2019 \\ PUBLISHED: April 2020 \\ GUEST EDITORS: Jan Karlshøj \& Line Leth Christiansen \\ DOI: $10.36680 /$ j.itcon.2020.015 \\ Eran Haronian, PhD Candidate, \\ Seskin Virtual Construction Lab, Faculty of Civil and environmental Engineering, Technion - IIT; \\ haronian@campus.technion.ac.il \\ Rafael Sacks, Professor, \\ Seskin Virtual Construction Lab, Faculty of Civil and environmental Engineering, Technion - IIT; \\ cvsacks@technion.ac.il https://sacks.net.technion.ac.il/
}

SUMMARY: Road construction is fundamentally different to building construction, in terms of its products, the types of work and operations, and the resources used. One of the key differences from the point of view of planning and control of production flow is that roads are composed of geometrically continuous courses rather than discrete 'products', making work packaging difficult. Clearly defined work packages that comprise work performed on distinct products are central to lean construction methods of planning and control, such as the Last Planner System. We therefore propose a product schema which models road sections with distinct road course segments that are dynamically defined aggregations of 'roadels'. A roadel is a fine-grained vertical triangular prism object that can be dynamically aggregated with other roadels to represent a road course segment associated with a work package, a planned task, or an as-built section. The schema represents the continuous nature of road construction, and its discrete entities enable representation and computations of as-made work using the raw data obtained from machine-mounted sensors and land surveys. We describe the information schema and illustrate its use for computation and analysis of lean production flow metrics. The schema has been tested using case study data from a 25,000 m2 parking lot project, which was modeled with more than 560,000 roadels with as-made status data collected from 33 working days over a period of two months.

KEYWORDS: building information modelling (BIM), information schema, lean construction, road construction, roadel

REFERENCE: Eran Haronian, Rafael Sacks (2020). ROADELS: discrete information objects for production planning and control of road construction. Journal of Information Technology in Construction (ITcon), Special issue: 'ECPPM 2018', Vol. 25, pg. 254-271, DOI: 10.36680/j.itcon.2020.015

COPYRIGHT: (C) 2020 The author(s). This is an open access article distributed under the terms of the Creative Commons Attribution 4.0 International (https://creativecommons.org/licenses/by/4.0/), which permits unrestricted use, distribution, and reproduction in any medium, provided the original work is properly cited. 


\section{INTRODUCTION}

Many Building Information Modelling (BIM) tools have native schema that represent buildings and building objects in ways that support not only design, analysis and detailing, but also project management (Sacks et al. 2018). Task-specific BIM tools are also available for the detailed production planning and control functions that are part and parcel of Lean Construction tools such as the Last Planner System ${ }^{\circledR}$ (LPS) (Ballard 2000). Like most BIM technologies and tools, the IFC information schema (ISO 2013) was developed originally for building construction projects, with hierarchical and well defined products (elements and spaces), and its schema contains the entities and relationships needed for exchange of production planning and control information.

Road construction is fundamentally different to building construction. Road courses are continuous products with amorphous shapes that do not lend themselves to subdivision into parts that can be associated with distinct work planning activities. For detailed production planning and control that includes a make-ready process, weekly work planning and monitoring of planning effectiveness and of production flow, the information schema must enable dynamic subdivision of the project into sub-products for definition of work packages and for aggregation into asbuilt sub-product representations that represent the work done, as measured by field surveys.

Existing BIM tools for design and construction of roads do not provide the level of detail and the relationships needed in their native schema for effective production control of earthworks. Likewise, the IFC Alignment (the first extension of the IFC schema for infrastructure, adopted in 2015) enables location of objects with relation to road, rail or bridge alignment curves (Amann et al. 2015), but it does not address the representation of road courses or production segments that is needed for production planning and control. The unique production processes and operations that characterize road construction projects, as well as the unique products they create, call for a thorough reconsideration of how those products should be modelled, and what data representations are needed to support production planning and control.

In this paper, we propose a product schema for lean construction production planning and control of the earthworks and surfacing operations of road construction projects. An analysis of the principles of production flow provides the foundation for definition of the use cases considered, and the use cases in turn lead to development of an information model. Following the review of the literature in the next section, we define four basic use cases according to the Plan Do Check Act (PDCA) cycle of production control. We then lay out the proposed information schema and illustrate its use for computing both planning and production metrics for a road construction project. The paper concludes with discussion of the considerations for binding the proposed schema to the IFC standard, of the earned-value and the production flow metrics, and of the limitations of the schema.

\section{BACKGROUND AND LITERATURE SURVEY}

\subsection{Production control for road construction}

Building construction projects can be conceived of as assemblies of discrete products. In most cases, there is direct correlation between the location breakdown structures (LBS) and the product breakdown structures (Kenley and Seppanen 2010). For instance, a residential building's LBS will include a hierarchy of floors, apartments and rooms - all of which constitute discrete components of the final product. These sub-products contain discrete elements that in many cases are manufactured in off-site factories and only assembled on site. Accordingly, various production strategies can be implemented; for application of exterior plaster, for example, it might be appropriate to work in batch flow, while for production of customized kitchens it might be appropriate to work in a job shop, and so on. Understanding the uniqueness of each product and process leads to choosing the most appropriate strategies.

In contrast to building construction projects, in road construction, the layers that constitute the finished product are continuous in nature, not discrete. When analyzing the production process of roads, characteristics of continuous flow and process manufacturing are found:

- Material processing is a core component of production: excavating, grinding, compacting, paving, etc.

- Real time quantity calculation systems are required for controlling consumed resources and for monitoring production status.

- Finished products can be disassembled only through demolition (unlike assembled components in a building).

Although road construction does involve sub-processes that have discrete products (bridges, culverts and other structures), the dominant process is continuous flow and process manufacturing. Table 1 summarizes some of the key differences between building and road production systems. 
Table 1. Comparison of building and road construction.

\begin{tabular}{|c|c|c|}
\hline & Road construction & Building construction \\
\hline Product & $\begin{array}{l}\text { One of a kind } \\
\text { Continuous } \\
\text { No customization } \\
\end{array}$ & $\begin{array}{l}\text { One of a kind } \\
\text { Discrete } \\
\text { High customization } \\
\end{array}$ \\
\hline \multirow[t]{3}{*}{ Process } & $\begin{array}{l}\text { Materials produced on site (by digging, crushing } \\
\text { and mixing) }\end{array}$ & $\begin{array}{l}\text { Primarily components manufactured in a } \\
\text { factory, transferred to site and installed }\end{array}$ \\
\hline & $\begin{array}{l}\text { Much of the work is "material processing" } \\
\text { Few task types, few subcontractors }\end{array}$ & $\begin{array}{l}\text { Much of the work is "assembly" } \\
\text { Many task types, many subcontractors }\end{array}$ \\
\hline & $\begin{array}{l}\text { Location breakdown structure is governed by } \\
\text { external constraints } \\
\text { Technological and safety aspects prevent } \\
\text { execution of several tasks simultaneously in the } \\
\text { same working area }\end{array}$ & $\begin{array}{l}\text { The location breakdown structure is defined by } \\
\text { the sub-products (floors, apartments, etc.) } \\
\text { Several tasks can be performed simultaneously } \\
\text { in the same working area }\end{array}$ \\
\hline Resource & Heavy machinery is the main resource & Professional workers are the main resource \\
\hline
\end{tabular}

According to Schmenner (1993), production strategies located on the main diagonal of the product-process matrix shown in Figure 1 represent an alignment between the product and the process. Deviation from the main diagonal reflects inferior strategies that increase costs and wastes. A downward deviation leads to "out-of-pocket costs", where unnecessary resources are invested in the process. For example, automating production for a "one of a kind" product would be wasteful due to the extensive overhead required. An upward deviation from the diagonal leads to "opportunity costs", where the proper resources are not invested in equipment or in automation.

Road construction projects can be considered to constitute unique, single "one of a kind" products (in terms of design, external conditions and constraints). However, the project in fact consists of many standard continuous sub-products, which positions them to the far right of the product mix axis in Figure 1. Road construction involves a well-defined, inflexible sequence of operations, and each operation requires dedicated equipment, suggesting placement near the bottom of the process pattern axis (at "line flow: paced by machines"). However, in practice, planning and control of the sequence of execution of the sub-products in the field relies entirely on the superintendent's professional experience and leadership (like a craftsman in a workshop), which derives from conceptualization of the project as "one of a kind". This practice ignores the flow aspects of the sub-products highlighted by Koskela in the Transformation-Flow-Value theory (Koskela 2000). The result is that road sections often experience long cycle times and the scope of work in progress remains high throughout most projects (Hopp and Spearman 2011).

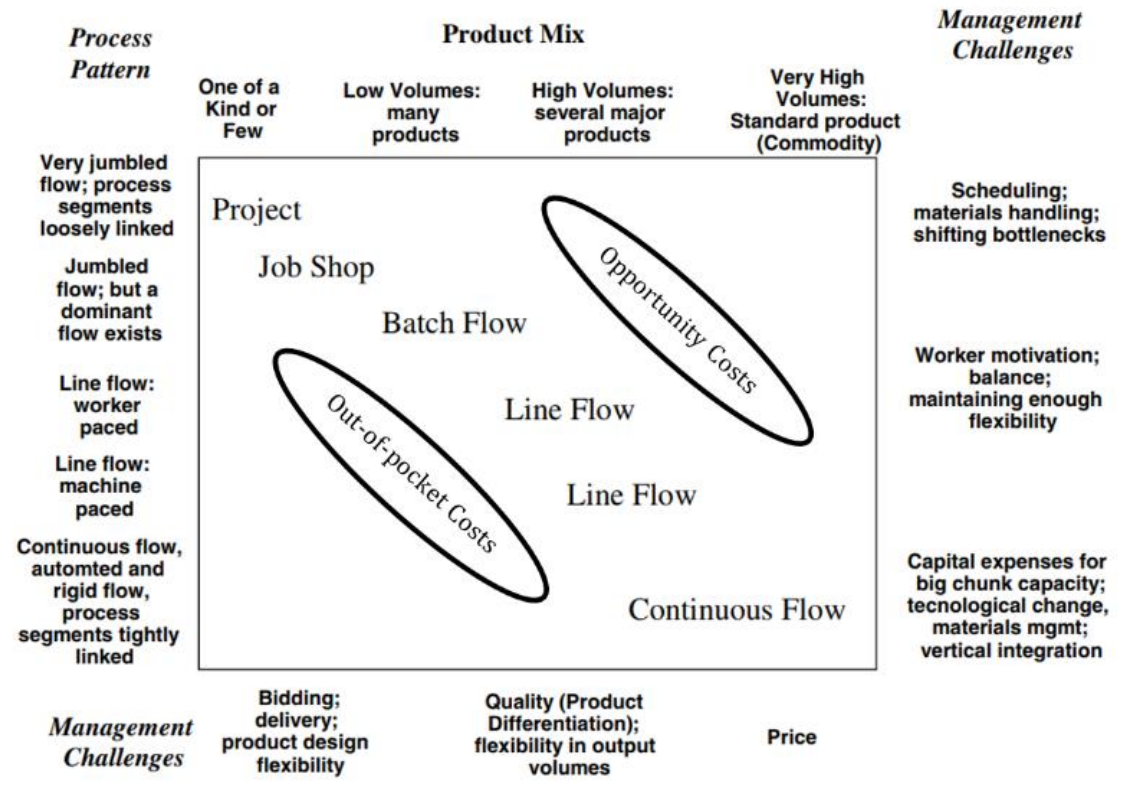

Figure 1. Product-process matrix (Schmenner 1993). 
Despite significant industry adoption of automated guidance and monitoring technologies for road construction equipment, productivity has not improved significantly over the period 2002-2016 (Sveikauskas et al. 2018). The new technologies provide an enormous amount of raw data, yet questions arise regarding what to do with this data and how to analyze it in the context of process flow.

The first question is how to associate the data with the products. In the absence of discrete product objects in the information schema, there is no direct relationship between the digital terrain models that are collected and the work packages into which the road is divided for execution, because the work packages themselves do not have specific geolocations. Data is therefore associated only with the earthmoving equipment whose sensors collect it. This enables local and operational use of the data, for example to optimize engine idle time or to avoid unnecessary repeat passes of equipment across the same path. According to Shingo "process analysis examines the flow of material or product; operation analysis examines the work performed on products by worker and machine (Shingo and Dillon 1989)." It appears that the current modes of technology application apply to the operations alone, failing to inform control of the production process.

Thus, the second question is how to use the data acquired to compute meaningful metrics of process flow. Existing metrics, such as the Percent Plan Complete (PPC) metric of the LPS (Ballard 2000) or the Construction Flow Index (CFI) (Sacks et al. 2017), are calculated using the production data associated with fine-grained definitions of tasks, which themselves are derived from work packages that comprise specific building model objects. Without delineation of products at the level of resolution needed for weekly, or even daily production planning, one cannot apply the digital terrain model data to compute production flow metrics.

\subsection{Information Schema for Infrastructure}

Development of information schema for infrastructure construction is not a new topic (Rebolj et al. 2008). LandXML, for example, has been used for civil engineering design and for analyses of survey measurement data for almost two decades. The LandXML schema provides an object-oriented multi-domain data interoperability instrument, including representation of solid model geometry (landxml.org). It does not, however, provide the objects or relationships necessary to represent a product breakdown structure nor a location breakdown structure, as do Building Information Modelling (BIM) schema (Sacks et al. 2018).

BIM technologies, and the IFC information schema that supports them, were developed for building construction projects. Their schemas represent buildings with hierarchical compositions of discrete, distinct and well-defined product entities (Björk 1992). Infrastructure facilities include a variety of element types, comprising unique products that require spatial product modelling approaches, and extensions to the IFC data schema have been proposed to represent infrastructure projects, such as roads, bridges and tunnels (Liebich et al. 2013). IFC Alignment, introduced in 2015, is the first extension of IFC for infrastructure and it is designed to deal with particular aspects of linear projects by enabling the association of physical elements with continuous vertical and horizontal alignments (Amann et al. 2015). Similarly, Vilgertshofer et al. (2016) proposed an extension of the IFC schema for shield tunnels.

Yet the representations obtained in these IFC schema extensions do not reflect the continuous nature of the courses (layers) of roads, whose geometric extents need to be defined arbitrarily and dynamically to reflect the ways in which the work itself is structured and restructured as the process emerges. Unfortunately, the IFC Alignment extension does not add this functionality. The primary spatial hierarchy does not extend beyond discrete, distinct and well-defined product entities (See “Class Diagram”, Liebich 2014 p. 4).

\subsection{Summary}

The IFC information schema and its infrastructure alignment extensions cannot represent the product and process information needed for production control of road construction. For road construction to benefit from new production control tools such as the LPS and from new technological innovations (e.g. information technologies, remote sensing and automation), the continuous and dynamic nature of the products, the ways in which they can be divided into sub-products and aggregated, and how they can be associated with fine-grained production planning and control tasks, must be reconsidered. The fundamental difference between the products and processes in road construction compared to building construction, substantially impacts the representing information schema.

The more precisely and appropriately the product is defined to suit the process, the more efficient production management can be. Yet, as described above, implementation of these principles is not trivial for continuous products. This work therefore deals with the dynamic subdivision of continuous elements into finite sub-elements from a production perspective. The subdivision supports dynamic aggregation of the sub-elements to represent changing work-packages and ad hoc as-built road segments. This is relevant not only for Lean production planning 
and control, but also for quality management (assignment of laboratory tests to specific areas), road maintenance (rehabilitation of certain areas on the road), and possibly for construction project domains with similar characteristics.

\section{USE CASES}

A set of four use cases, based on the well-known Plan-Do-Check-Act process (Deming 1986; Shewhart 1939), defines the extents of the Lean production planning and control processes for road construction. The purpose of these use cases is to describe the proposed procedures of production planning and control in road construction, as a basis for specifying the information flows and the data structures needed to support them. As can be seen in the UML use case diagram (Figure 2), the procedures include concepts from the Last Planner System® (Ballard 2000) - such as weekly work planning, a make ready process and look-ahead planning - as well as the new concepts and technologies specific to the continuous nature of the roads and the ways in which production flow might be monitored and evaluated in this context.
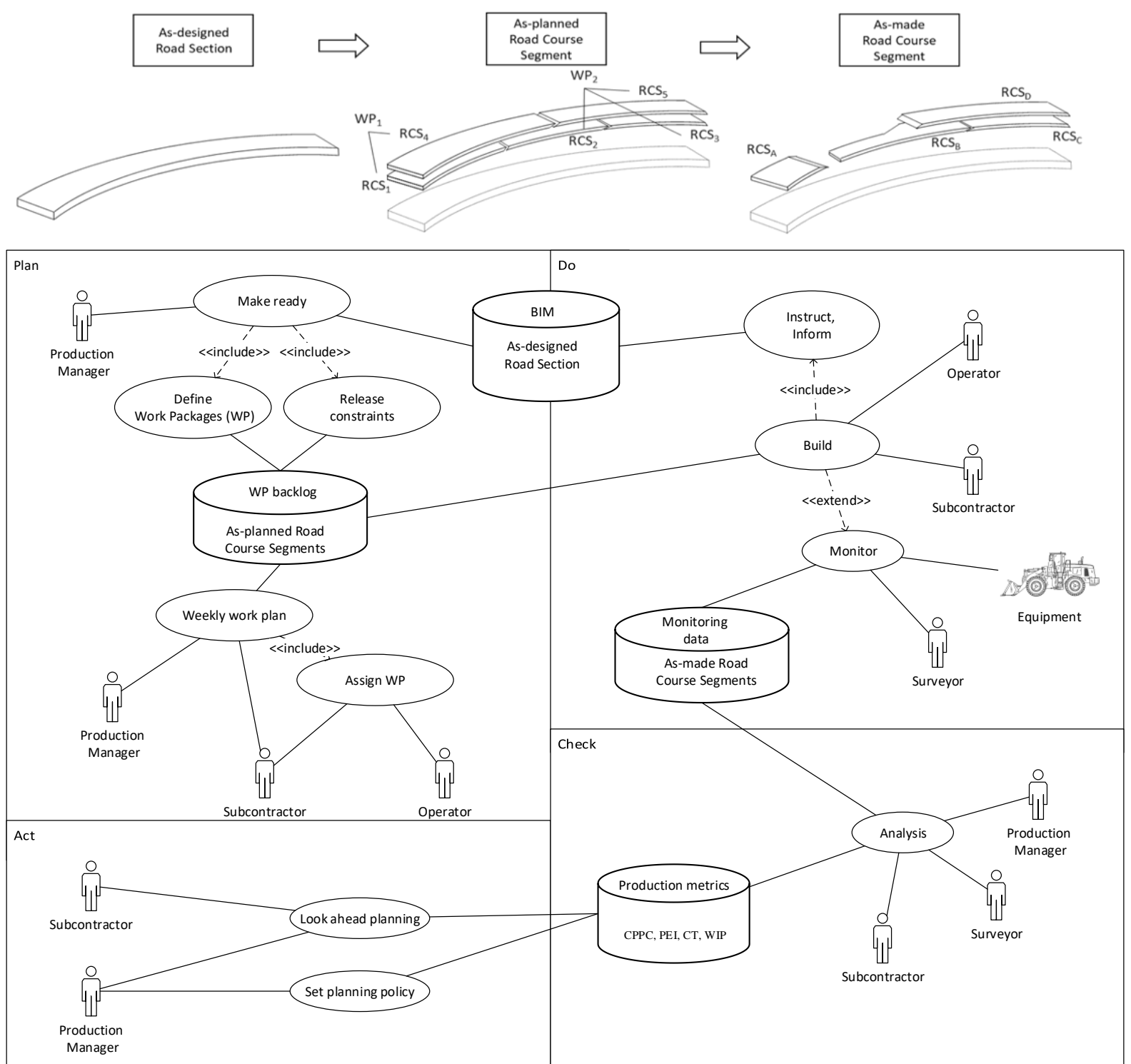

Figure 2. Overview of use cases for Lean production planning and control in road construction.

The first use case is "Plan". The basic requirement for planning is an accurate definition of work packages. In continuous and layered elements like roads, the main element (the road or the road courses) must be divided into layered sub-components that can be used to define work packages. The different layers of a road require specialized heavy equipment and are carried out at different accuracy levels according to each layer's function and material. 
For each layer, several operations are needed (such as spreading, compacting, finishing, etc.), and each operation requires a corresponding set of heavy equipment. The work package sizes are determined by the characteristics of the operations and the equipment, and vary significantly in composition and size. In addition, physical constraints imposed by infrastructure (pipes, cables) along the route of the road must also be considered when setting work packages. Therefore, the flexibility to divide the main elements into segments that will change over time throughout the project is a key requirement.

The second use case is "Do", in which work is executed. The information flows in this use case include delivery of the work package information to the equipment operators and monitoring the work in real-time. This includes collection of raw data obtained from GPS or grade control systems installed on heavy equipment, as well as raw data collected by other sensors, laser scanners or aerial imagery. The ability to produce value from this data lies in the ability to represent it in relation to the planned work, which requires appropriate entities and relationships in the information schema.

The third use case is "Check". Once the work has been performed and monitored, managers need to analyze the status of the project. We distinguish between two types of analysis. The first refers to the reliability of the planning system, and the ability of the "last planners" to implement the planned work-packages. The second analysis refers to the quality of the product flow and is expressed with production parameters such as cycle times, work in progress, throughput, value adding times and non-value adding times. The two types of analysis are thoroughly detailed in Section 5 below, but suffice it to say here that the essential basis for these analyses is the ability to store all of the monitoring data within the information schema.

The final stage of the PDCA cycle, "Act", constitutes the required managerial policy decisions. In this stage managers and planners review the quality of planning and the status of production, using the outcomes of the previous "Check" stage. Thus, emphasis is placed on functions to visualize the planning and the production metrics; this aspect too is detailed and demonstrated in Section 5 below. Policy decisions at this stage may lead to changes in the nature of the operations, the sizes of the work packages and the supply levels of equipment and other resources, and therefore the schema must support straightforward, flexible and user-friendly functions to effect such changes.

These four use cases lay the foundation for definition of a supportive information schema, with an emphasis on the ability to dynamically divide a continuous road element into differential entities that can be aggregated into work packages.

\section{PROPOSED INFORMATION SCHEMA}

Based on the production process described in the use cases, we suggest additional levels of product hierarchy (Figure 3) that will enable dynamic distribution of continuous road elements into sub-products and their aggregation into work packages, while maintaining the continuous nature of the parent product element. The conceptual data schema, defined using UML class diagrams, is shown in Figure 4.

Table 2 lists the classes of the data schema. The first two classes define the road as it is designed. The Road Section is the primary physical designed object. The road section in this schema is the equivalent of the RoadElement object in the Ifc Alignment extension, which is a subtype of PhysicalElement. Roads are built in layers, called courses. The Road Course class allows definition of the layers - their material, thickness, degree of compaction and other operational parameters. The road sections have geometry and defined extents - the road courses only define the thickness of each layer within a road section.

The next two classes enable the specific functionality for Lean planning and control that was defined in the use cases. Road Segments define the physical extents of the segments used for work planning and monitoring, and they are designated either 'as-designed' or 'as-made' respectively. For planning purposes, their size - extents and depth - are set to suit the operations that are needed to build the road (e.g. spreading, compacting, grading, surfacing, each of which are done by different machines with differet optimal section extents). They do not necessarily have uniform depth.

The geometry of a road segment is defined as an aggregation of layers of solid prismatic road elements, or Roadels. Roadels are discrete parts of a road section, just as a picture element - a pixel - is a discrete part of a digital image. Each roadel carries a set of elevation values, and every elevation value is also associated with a road segment. In this way, every elevation value is identified as 'as-designed' or 'as-made', through its association with a road segment. The road segment also carries a date, which is the date of design for 'as-designed' elevations, and the date of measurement for 'as-made' elevations. Likewise, the road segment carries a data source property for the designer or the piece of equipment which made the measurement (a land survey, a drone, a grader, compactor, etc.). Every 
pair of adjacent 'as-designed' elevation values defines the particular 'slice' of the roadel that belongs to the corresponding as-designed road course. Similarly, every pair of adjacent 'as-made' elevation values defines the slice of the roadel that was executed between the dates on which each elevation value was measured.

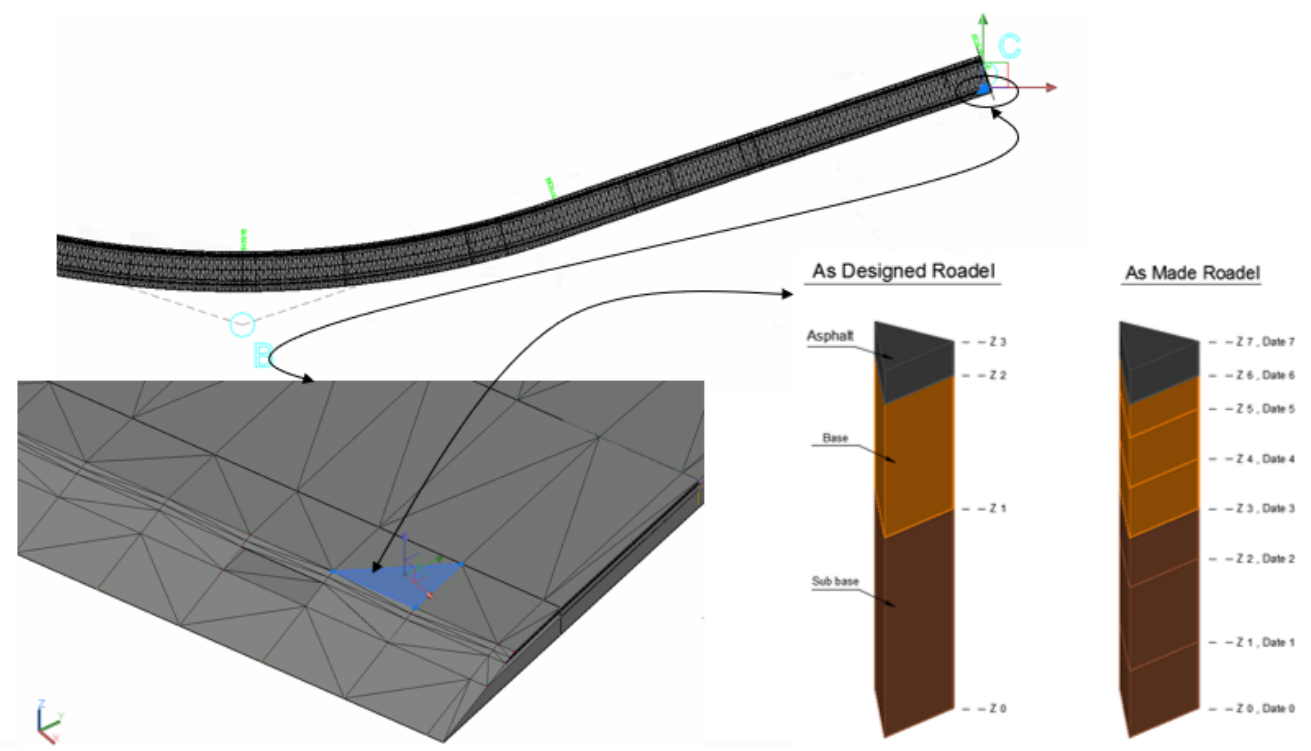

Figure 3: A schematic illustration of the data schema

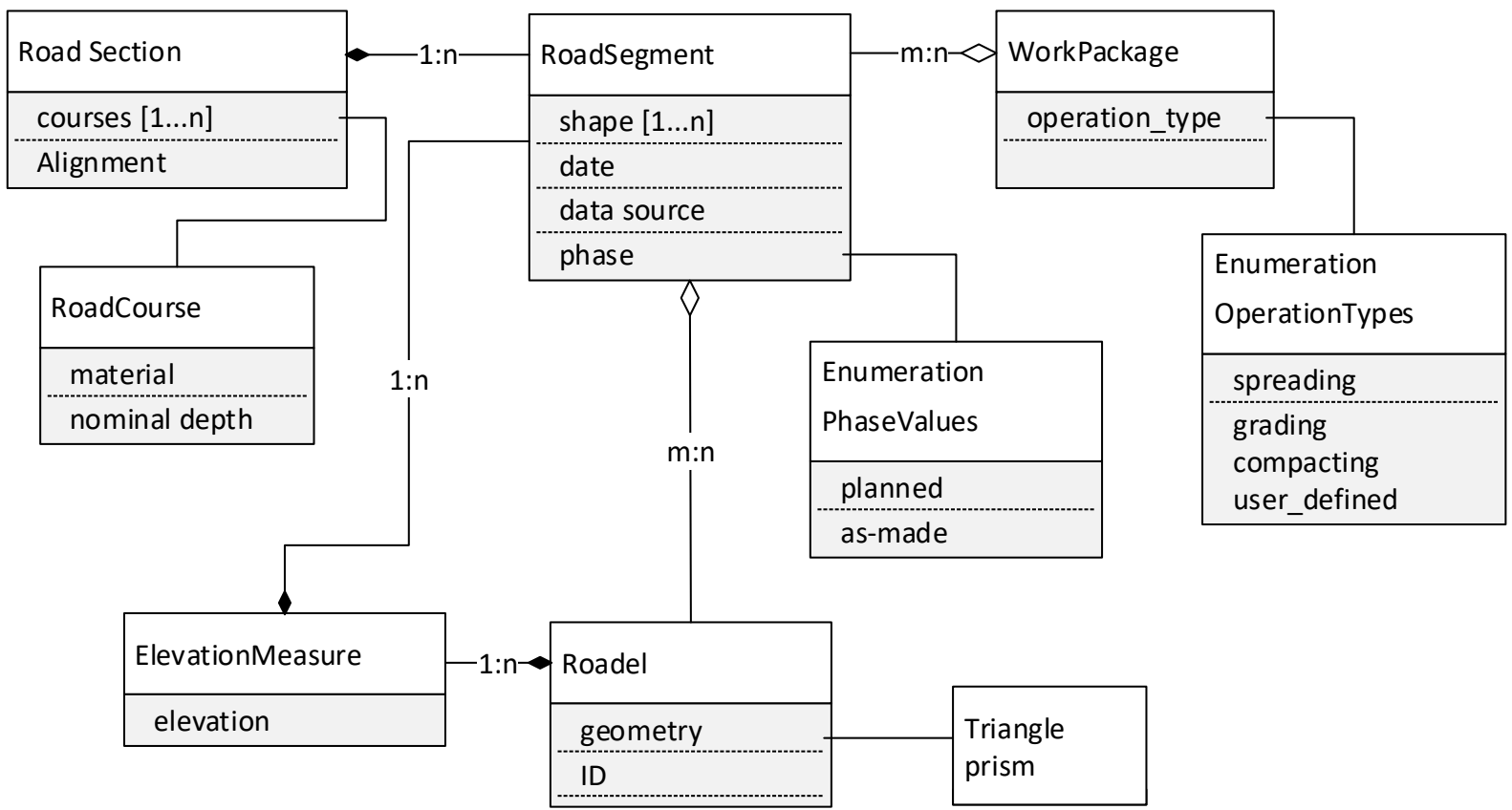

Figure 4. UML class diagram depicting the conceptual data schema

The horizontal prismatic shape of a roadel is a triangle, which is a part of a Triangulated Irregular Network (TIN) that covers the full geographic extent of the project. The TIN is delineated a priori, at the start of the project, subject to two specific criteria:

1) The size of the roadels is set to match the minimum degree of resolution required for production control.

2) The edges of roadels are aligned with the edges of any and all physical product boundaries. i.e. no roadel edges cross any material boundary. For example, where a road course segment represents a row of curbstones, the perimeter of the set of roadel triangles underlying that part of the road will exactly match the perimeter of row of curbstones, and the dimensions of the roadel triangles will be no larger than the width of the curbstones. 
The second criterion ensures that every 'as-designed' roadel slice (the vertical triangular prism between any two adjacent roadel elevation values) will be homogenous in terms of its material. By extension, this also means that when work is performed, monitoring will assume that the full horizontal extents of a roadel slice surface are of uniform material; however, an 'as-made' slice may or may not be of uniform material if measurements were missed between operations.

The top elevations of a set of roadels aggregated together in a road course segment define the upper surface of the road segment. This may be the as-designed surface, or an intermediate as-made surface measured at some given point in time during construction.

Table 2. Definition of classes for road production planning and control.

\begin{tabular}{|c|c|}
\hline Class & Definition \\
\hline Road Section & A road section represents the product as designed. \\
\hline Road Course & $\begin{array}{l}\text { A designed layer of a road section, e.g. 'base course'. A set of road courses } \\
\text { define a road section's structure in the same way that a wall is defned by its } \\
\text { composite layers. }\end{array}$ \\
\hline Road Segment & $\begin{array}{l}\text { Define the physical extents of the segments used for work planning and } \\
\text { monitoring; 'as-designed' or 'as-made' respectively. The geometry is defined } \\
\text { as an aggregation of layers of Roadels. }\end{array}$ \\
\hline Roadel & A triangular prismatic primitive element of a road section. \\
\hline Work Package & $\begin{array}{l}\text { An aggregation of 'as-designed' road segments on which a single particular } \\
\text { operation type (e.g. compaction) is to be executed as a distinct package. }\end{array}$ \\
\hline
\end{tabular}

\section{PRODUCTION DATA ANALYSIS}

In this section, we illustrate use of the information schema for computation of four lean production planning and control metrics. The data analysis is demonstrated on a simple project, the construction of a large parking lot, illustrated in Figure 5. The example considers a single operation, performed on the whole area of the parking lot over a period of some two months. Surface elevation measurements were made during every working day using the Trimble GCS900 Machine Control GPS survey equipment mounted on the heavy equipment that performed the work (see Figure 6). The elevation values were processed and stored using Trimble VisionLink and Trimble Business Center software.

The first new analysis type focuses on production planning. The metrics are the Continuous Planned Percentage Complete (CPPC) and the Planning Effectiveness Index (PEI), both of which measure the success of the planners in setting work-packages, identifying production constraints and working to make the tasks ready, and allocating resources in an effective manner that will stabilize the production system. The second new analysis type focuses on the quality of the product flow. The metrics are the quantity of Work in progress (WIP), the cycle time for a typical product (CT), the throughput rate of the system as a whole (TH), value adding vs. non-value adding working time, and the Continuous Construction Flow Index (CCFI). Using quantitative examples, we demonstrate how well-established parameters from the field of production planning and control, which hitherto have not been applied to continuous flow products in road construction, can be computed using the proposed information schema.

The traditional way to monitor construction progress is the earned value (EV) method. As a benchmark, we begin by presenting (in Figure 7) the cumulative EV graph for the examined period. Cut and fill values can be generated directly from the Trimble VisionLink software. The EV was calculated for the sum of the cut and fill volumes along the examined period. The first principle difference between the EV measure and the production planning and flow indices is that the latter are based on discrete products, expressed in the form of roadels, which have discrete locations. Therefore, the raw data must be imported into the database according to location. The Trimble VisionLink software enables export of a surface on a regular grid that represents the highest elevation of each grid point encountered by the machine in any given time interval.

For the purposes of production control, an interval of one working day was selected, as this matches the natural work rhythm. The data import proceeds according to the flowchart depicted in Figure 8 . The first step is to check if work has been performed on each roadel, by determining whether its center of gravity falls within a cell of the 
surface grid of the acquired road section surface. If so, a new elevation value is recorded and associated with the roadel and with the 'as-made' road section object.

To demonstrate the computation, the information schema was implemented in a set of Excel worksheets. Table 3 displays a set of elevation measures, which are associated with roadels and with road coarse sections. Each row in the table represents a single roadel, and each column represents a road course section, measured by a given machine on a particular working day. The cells display the last elevations extracted using the algorithm depicted in Figure 8 from the surface data measured by the machine on that day. A blank value in a cell indicates that no work was performed on that day. Note that this procedure does not use all the raw data collected by the machines: it does not use machine engine telemetry data, and it uses only one elevation level per day (the raw data can be recorded every second or less).

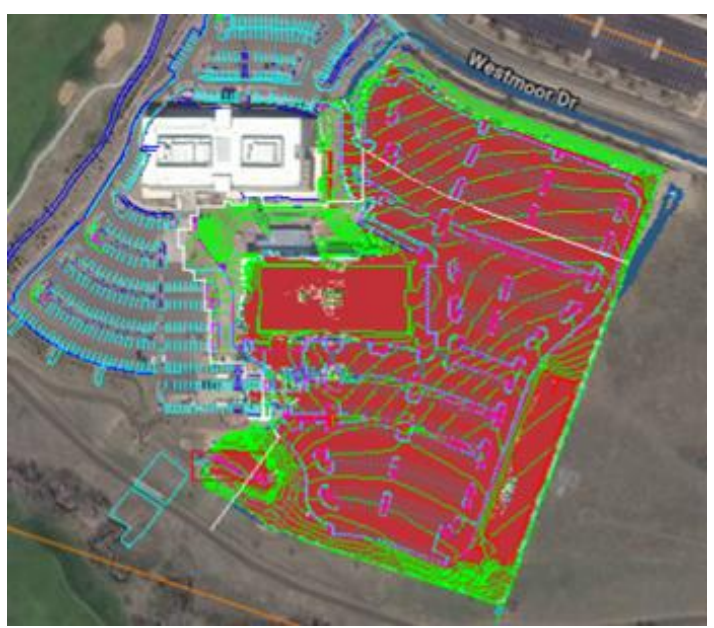

Figure 5: A plan view of a large parking lot project. The red area indicates the coverage area of the earthworks where equipment made eight or more passes (image from Trimble VisionLink).

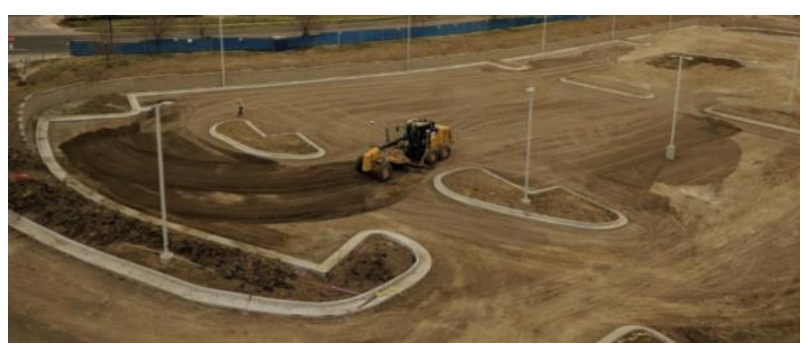

Figure 6: A grader with a Trimble GCS900 Machine Control system working on the northwest corner of the parking lot.

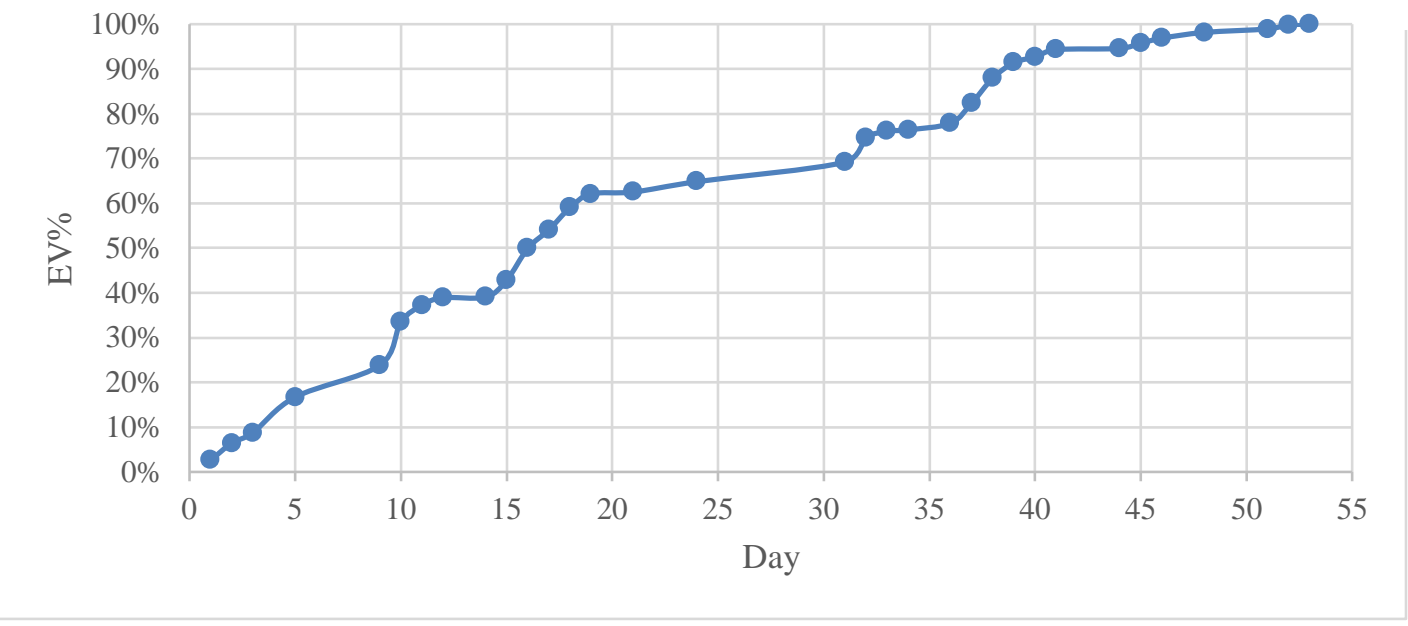

Figure 7: Cumulative volume of earthworks, representing earned value (EV) for the demonstration project. 


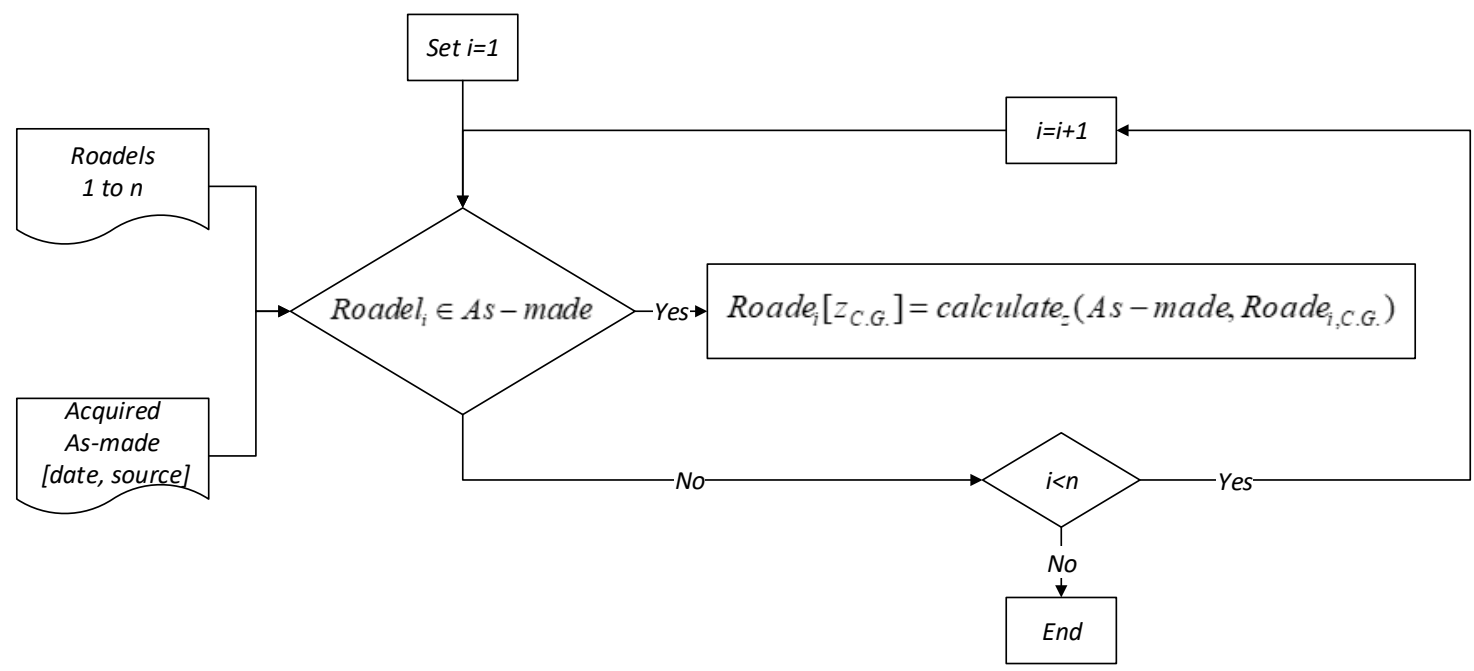

Figure 8: Data import procedure.

Table 3: Data table showing elevation measures (in the cells) [in $m$ units] associated with roadels (table rows) and with road segments (table columns).

\begin{tabular}{|r|l|l|l|l|l|l|l|}
\hline \multirow{2}{*}{\begin{tabular}{r} 
Road \\
\multirow{2}{*}{ Segment }
\end{tabular}} & Date & $30 / 04 / 2018$ & $01 / 05 / 2018$ & $04 / 05 / 2018$ & $08 / 05 / 2018$ & $09 / 05 / 2018$ & $10 / 05 / 2018$ \\
\cline { 2 - 8 } & Phase & as-made & as-made & as-made & as-made & as-made & as-made \\
\cline { 2 - 8 } & $\begin{array}{c}\text { Data } \\
\text { Source }\end{array}$ & $\begin{array}{l}\text { grid } \\
\text { control }\end{array}$ & $\begin{array}{l}\text { grid } \\
\text { control }\end{array}$ & $\begin{array}{l}\text { grid } \\
\text { control }\end{array}$ & $\begin{array}{l}\text { grid } \\
\text { control }\end{array}$ & grid control & $\begin{array}{l}\text { grid } \\
\text { control }\end{array}$ \\
\hline 229724 & $1,664.99$ & $1,665.03$ & $1,664.97$ & $1,664.80$ & $1,664.94$ & $1,664.94$ \\
\hline 229725 & $1,665.01$ & $1,665.02$ & $1,664.99$ & $1,664.77$ & $1,664.86$ & $1,664.82$ \\
\hline 229726 & $1,664.99$ & $1,665.01$ & $1,664.99$ & $1,664.73$ & $1,664.85$ & $1,664.84$ \\
\hline 229727 & $1,664.99$ & $1,664.98$ & $1,664.98$ & $1,664.32$ & $1,664.57$ & $1,664.87$ \\
\hline 229728 & $1,664.97$ & $1,664.96$ & $1,664.30$ & $1,664.70$ & $1,664.85$ & $1,664.53$ \\
\hline 229729 & $1,664.95$ & $1,664.95$ & $1,664.60$ & $1,664.66$ & $1,664.84$ & $1,664.88$ \\
\hline
\end{tabular}

\subsection{Metrics of planning reliability}

In the Last Planner $\circledast$ System, the basic planning reliability assessment metric is the Percent Plan Complete (PPC), a basic measure of how well the planning system is working. According to the Lean Construction Institute, the PPC is "the number of promises/activities completed on the day stated divided by the total number of promises/activities made/planned for the week ("LCI Lean Project Delivery Glossary" 2017). It measures the percentage of assignments that are $100 \%$ complete as planned." Like most tools in LC, PPC was designed to support a production environment that is characterized by multiple interdependent tasks performed by multiple subcontractor trade crews. Thus, in PPC the emphasis is on full completion of tasks on time; partial completion of a task does not allow the next subcontractor to enter the location as planned.

In contrast, road construction production systems have greater flexibility, because they have relatively far fewer subcontractors and tasks, and the nature of the product and the work is continuous, so that the work boundaries between successive tasks can be fuzzy rather than sharp. For these reasons, we propose two alternative metrics that share a similar purpose to the PPC, but are designed for the continuous production environment of road construction. The first is the 'Continuous Percent Plan Complete' (CPPC), and the second is the Planning Effectiveness Index (PEI).

\subsubsection{Continuous Planned Percentage Complete}

The traditional PPC index consists of an aggregation of discrete Boolean values for each of the tasks that are included in a given work plan. Any task completed fully and on time is given a value of '1'; all other tasks are given a value of ' 0 '. A PPC of $60 \%$ means, for example, that six out of 10 tasks in a work plan were completed exactly as planned. 
In contrast, the proposed CPPC considers the continuous nature of road construction and the difficulty of defining sharp boundaries for the extents of products included in work packages, by setting a task completion threshold, $T C T$, in terms of the proportion of the work content of a task that must be completed for the following task to be started without delay or negative impact on its quality. The threshold value also assumes that the remaining portion can be re-assigned to the next work package of the same type. The production planning team must define the value of TCT according to the characteristics of the work type and the project's constraints.

Let $P_{i}$ be the amount of work actually performed on a given work-package $i$ in a given time interval. The units of $P_{i}$ are the same as the units of the planned work package content, $W P_{i}$, and are dependent on the work type. The completed proportion, $\alpha_{i}$, is the proportion of the work content of a task completed, calculated as $\alpha_{i}=P_{i} / W P_{i}$. If, for example, $T C T=95 \%$, then the CPPC can be calculated by summing across all planned work packages as follows:

$$
C P P C=\frac{1}{n} \sum_{i}^{n}\left[1\left|\alpha_{i} \geq T C T ; 0\right| \alpha_{i}<T C T\right]
$$

Note that $\boldsymbol{P}_{\boldsymbol{i}}$ is computed differently for different work types, to reflect the condition that starting the following task must be possible. For material spreading, for example, $\boldsymbol{P}_{i}$ would be the total volume of all roadels $j$ for which the elevation of the material spread has reached the planned elevation, because this is a necessary condition for compacting to begin for that set of roadels. $\boldsymbol{W P}$ for material spreading is the total volume of material for all the roadels in the work package. Specifically, if the as-planned depth of spread material for each roadel $\boldsymbol{j}$ is $\boldsymbol{d}$ plannedij, the planned top elevation is $\boldsymbol{h}$ plannedij, the as-made elevation reached is $\boldsymbol{h}$ as-madeij, and the area of a roadel is $\boldsymbol{A}_{j}$, then:

$$
W P_{i}=\sum_{1}^{m} A_{j} d_{i j}^{\text {planned }} ; P_{i}=\sum_{1}^{m} A_{j}\left[d_{i j}^{\text {planned }}\left|h_{i j}^{\text {as-made }} \geq h_{i j}^{\text {planned }} ; 0\right| h_{i j}^{\text {as-made }}<h_{i j}^{\text {planned }}\right]
$$

For material compacting, by contrast, $P_{i}$ would be the total area of roadels for which the number of passes of a compactor had reached or exceeded the planned number, for the given compacting machinery.

\subsubsection{Planning Effectiveness Index}

The Planning Effectiveness Index (PEI) refers to the ratio of the planned work to the performed work. It answers the question "What proportion of the work actually performed, was planned work?" Here too, the metric corresponds to the continuous nature of the layered products in road construction, with the potential for fuzzy work package and location boundaries. Given $\boldsymbol{W}_{j}$ to be the work performed in roadel $j$ during a given planning period and $\boldsymbol{P}_{i}$ to be the work performed in roadels that belong to the work packages planned for execution in the same planning period, the PEI is calculated as follows:

$$
P E I=\sum_{i}^{n} P_{i} / \sum_{j}^{m} W_{j}
$$

Note that the total amount of work performed $\boldsymbol{W}_{\boldsymbol{j}}$ is summed across all roadels, not only the roadels that belong to planned work packages, as is the case for $\boldsymbol{P}_{\boldsymbol{i}}$. Thus, PEI will always be less than or equal to CPPC.

\subsubsection{Illustration of CPPC and PEI values}

To illustrate the CPPC and PEI, we consider four synthetic work packages defined for the example parking lot project, as shown in Figure 9. WP-1 to WP-5 refer to the five work packages for compaction of a road course (measured in area) and were planned for execution in a certain week. Data obtained from the sensors on the heavy equipment indicate the actual work performed throughout the week, as shown in Figure 10. This raw data is imported to the production planning and control database, enabling identification of the work performed on the roadels constituting the road section associated with work packages 1-5.

In Figure 11, the roadels that were planned to be compacted within work packages 1-5 for which the number of passes was adequate $(\Sigma \mathrm{Pi})$ are colored green; roadels that were part of WP-1 to WP-5 but were not sufficiently compacted are colored purple; roadels that were worked on but are outside of WP-1 to WP-5 are colored red; and all other roadels are colored cyan.

Table 4 displays the CPPC calculation basedon the planned area of WP-1 to WP-5 and the actual work complete $\left(\Sigma P_{i}\right)$. The overall planned area is 7,860 sqm, the total area of the work performed $\Sigma W_{j}$ is $7,274 \mathrm{sqm}$, and the area of $\Sigma P_{i}$ is $7,015 \mathrm{sqm}$. Given $T C T=90 \%$, the CPPC Received is $60 \%$. 


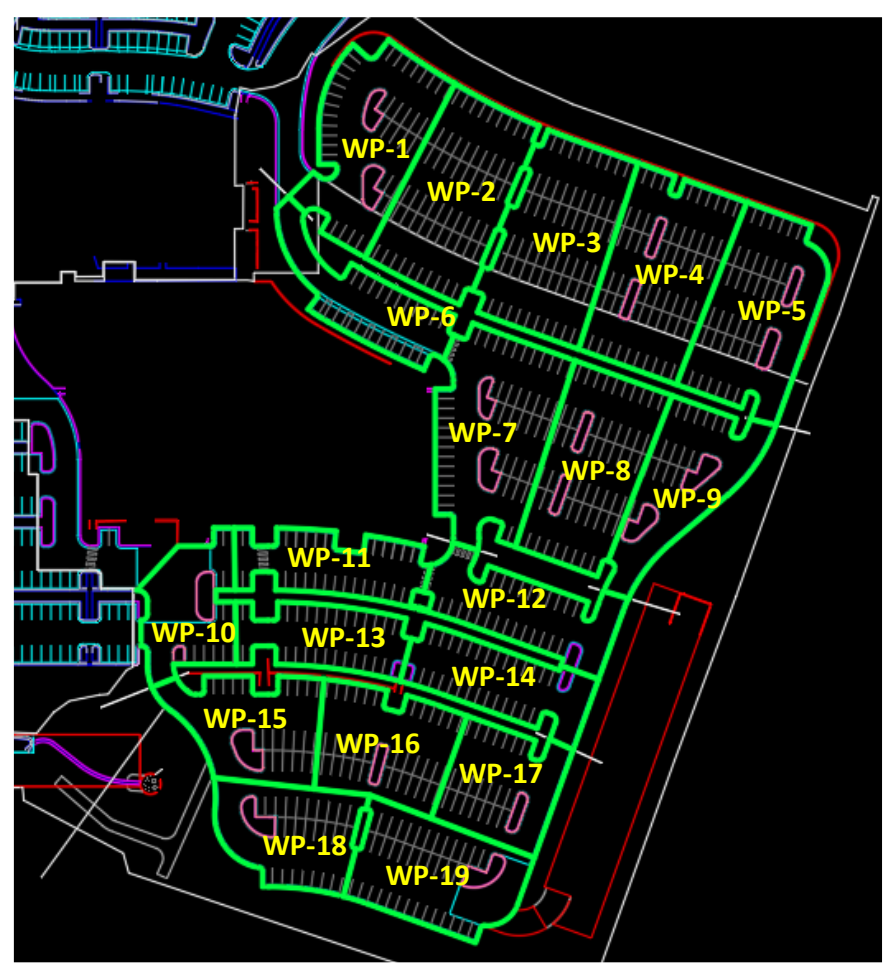

Figure 9: Work packages defined for the parking lot project.

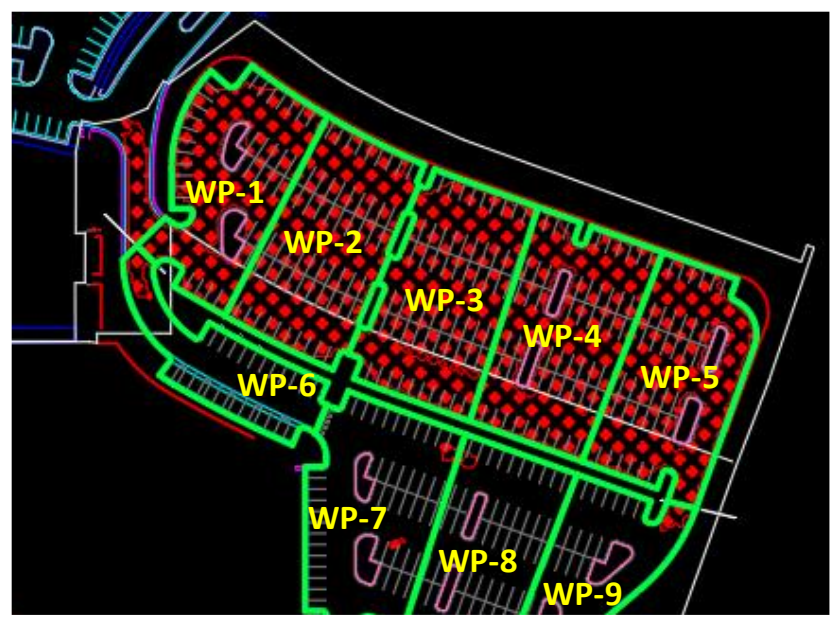

Figure 10: Actual work performed on WP-1 to WP-5

Table 4: CPPC calculation

\begin{tabular}{|c|c|c|c|c|}
\hline Work Package & $\begin{array}{c}\text { Work } \\
\text { planned } \\
W P_{i}[\mathrm{~m} 2]\end{array}$ & $\begin{array}{c}\text { Work } \\
\text { performed } \\
P_{i}\left[\mathrm{~m}_{2}\right]\end{array}$ & $\alpha_{i}=P_{i} / W P_{i}$ & $\begin{array}{c}\text { Complete } \\
{[0,1]}\end{array}$ \\
\hline WP-1 & $1,403.80$ & $1,185.80$ & $84 \%$ & 0 \\
\hline WP-2 & $1,617.70$ & $1,500.70$ & $93 \%$ & 1 \\
\hline WP-3 & $1,679.80$ & $1,533.70$ & $91 \%$ & 1 \\
\hline WP-4 & $1,650.50$ & 1490 & $90 \%$ & 0 \\
\hline WP-5 & $1,508.60$ & 1305.7 & $87 \%$ & 1 \\
\hline
\end{tabular}


Accordingly, CPPC can be calculated as the follows:

$$
C P P C=\frac{1}{5} \sum_{i}^{5}\left[1\left|\alpha_{i} \geq T C T ; 0\right| \alpha_{i}<T C T\right]=\frac{3}{5}=60 \%
$$

The PEI refers to the overall weekly work plan, and can be calculated as follows:

$$
P E I=\frac{\sum P_{i}}{\sum W_{j}}=\frac{75,517}{78,300}=96 \%
$$

In this synthetic example, the CPPC indicates that the reliability of the production system needs to be improved. However, the PEI shows that the majority of work performed was carried out on the planned work packages. According to the PDCA cycle mentioned in chapter 3, the 'Act' phase might include a size update for the subsequent work packages, or a change in the resource allocation that will enable completion of future work packages.

Note that the accuracy of the measurements depends on the resolution of the differential elements (the roadels). In this case, roadels were triangles of approximately $0.044 \mathrm{~m} 2$. For production system control at the level of the CPPC and PEI, this is more than adequate - there is no need for over-precision.

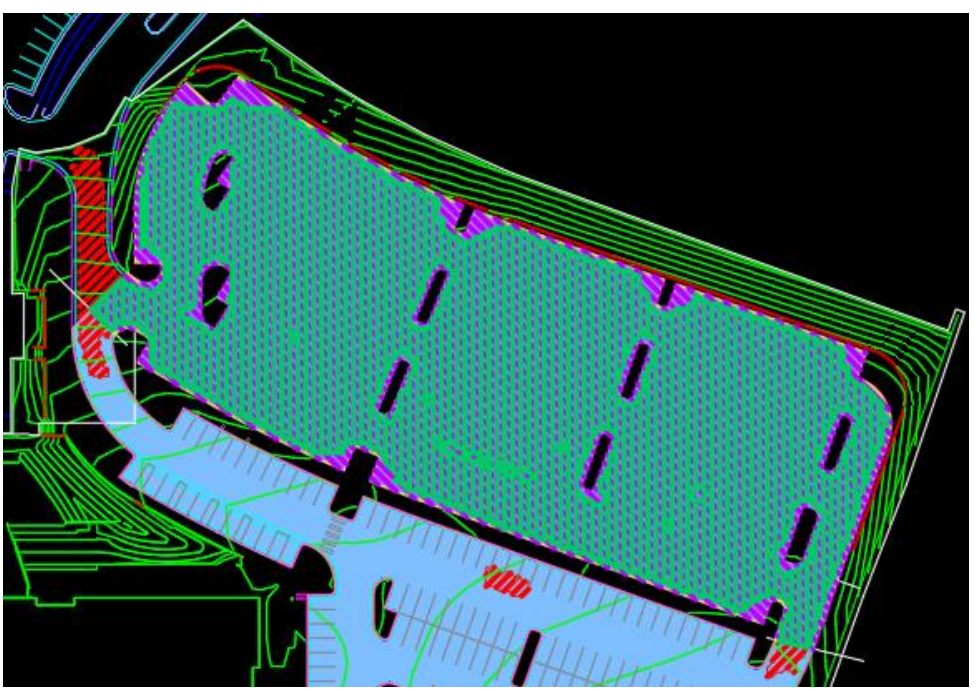

Road segments planned in WP-1 to WP-5 where work was not yet started or is incomplete

Road segments planned in WP-1 to WP-5 where work is complete

Road segments ('as-made') outside of WP-1 to WP-5 in which work was performed

Road segments planned for other work packages

Figure 11: As made WPI

\subsection{Metrics of production flow}

In this section we demonstrate how parameters typically used to evaluate production flow for discrete products such as product cycle times, value adding and non-value adding times, and work in progress (WIP) - can be computed for road construction projects on the basis of the proposed information schema. Additional parameters can be defined as needed, however we suffice with these for the purpose of demonstrating feasibility. The following paragraphs detail calculation of the production flow indices for the example parking lot project over a construction period of some two months.

Cycle times were calculated by computing the lag between the first operation and the last operation performed on each roadel. Given the date range constraints of the raw data available for the research, and for demonstration purposes only, we referred to the date of the first machine pass as the beginning of the production process and the date of the last machine pass as the end of the process. Since the 'as-made' elevations for each roadel are linked to the road sections and thereby to the dates on which they were recorded, identifying the first and last elevations for each roadel is straightforward. The results can be conveniently portrayed on a color-coded map of the project, as shown in Figure 12. From a lean production perspective, roadels with short cycle times (shaded green) represent good production flow, whereas roadels with long cycle times (shaded red) contribute to high levels of WIP and often require rework. The red strip at the center right was apparently used as a temporary daily access route, with the result that the roadels were 'occupied' for a long period.

Waiting times (non-value adding times) are computed as the sum of the time intervals between operations performed on each roadel along the process. In Figure 13, the waiting times are visualized and color coded. Areas with the shortest waiting times are shaded green and areas with longer idle times are shaded red. The implication is that the red areas experienced many days during which no work was performed. 


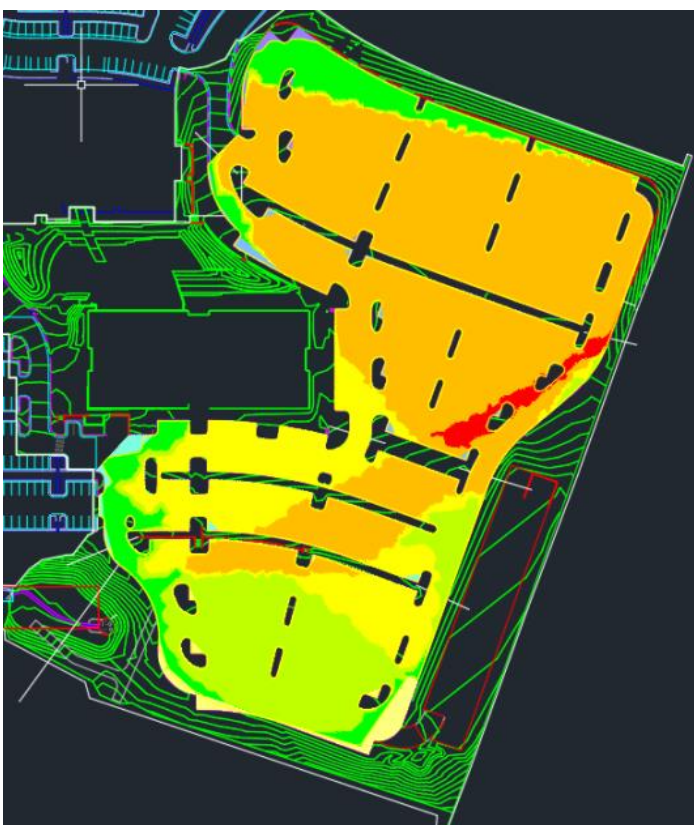

Figure 12: Cycle times displayed in a color-coded plan view.

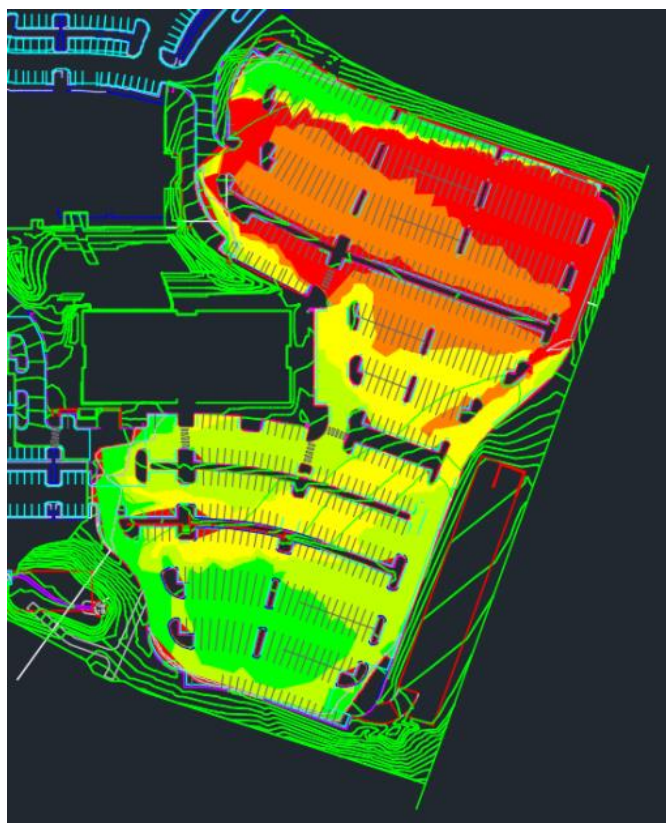

Figure 13: Waiting times displayed in a color-coded plan view.

Work in progress (WIP), a parameter that reflects the quantity of products that are under production at any given time, is computed as the sum of the areas or of the volumes of roadels whose production had begun but is not yet complete at any given time. The work status for any course - in progress or complete - can be derived easily because the design level for the course at every roadel is known. Figure 14 show the progression of WIP through eight weeks of project execution with respect to the location of WIP, whereas Figure 15 displays the WIP level as a percentage of the total work volume over the same time period. Note that these are indicative only of the facility with which they can be computed, as they are based on data for a single operation rather than on the data for the full process).

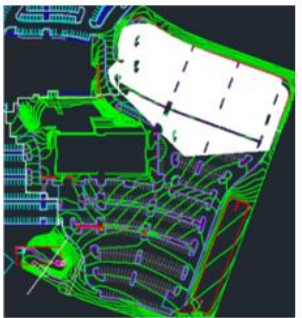

$1 / 5 / 2018$

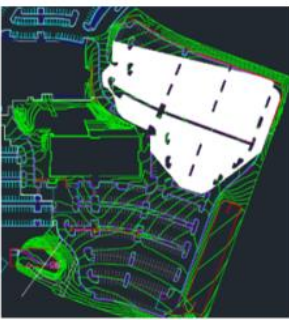

$10 / 5 / 2018$

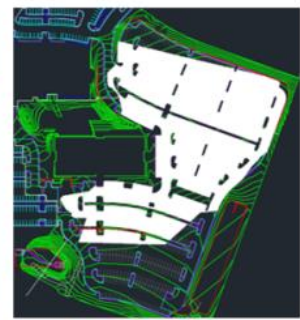

$20 / 5 / 2018$

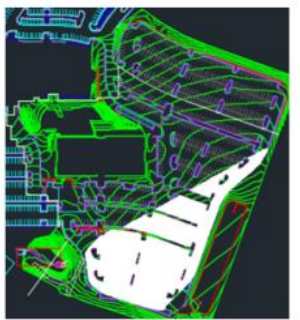

$15 / 6 / 2018$

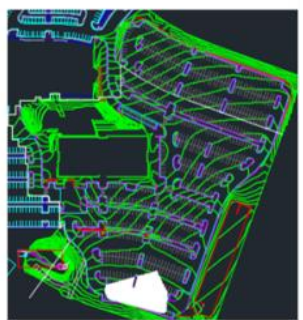

$22 / 6 / 2018$

Figure 14: Images showing the WIP at different times through the project duration.

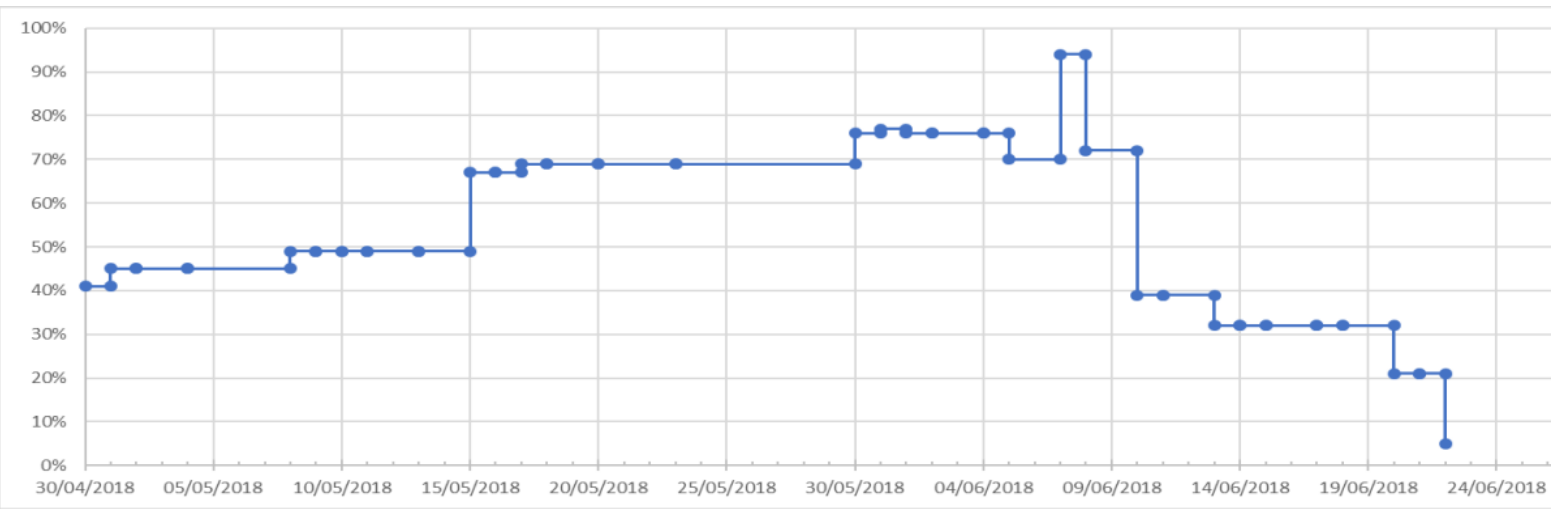

Figure 15: WIP growth and decline through the project duration. 
Finally, the data structure supports enquiry and display of the progress of each roadel through the production process, as shown in Figure 16. One can clearly see the change in elevation as the ground level was changed by the grader from day to day, and the long waiting time during which no work was done on the roadel. As production information is related to each roadel, production analysis can be performed on each discrete element. However, in practice, production managers are not concerned with individual roadels, but with the flow of the process as a whole, which means that clusters of adjacent roadels with similar behavior must be identified. This too is straightforward, as ranges of values for any of the flow parameters can be set and neighboring roadels with values that fall within the desired range can be easily filtered and aggregated in representative road coarse sections.

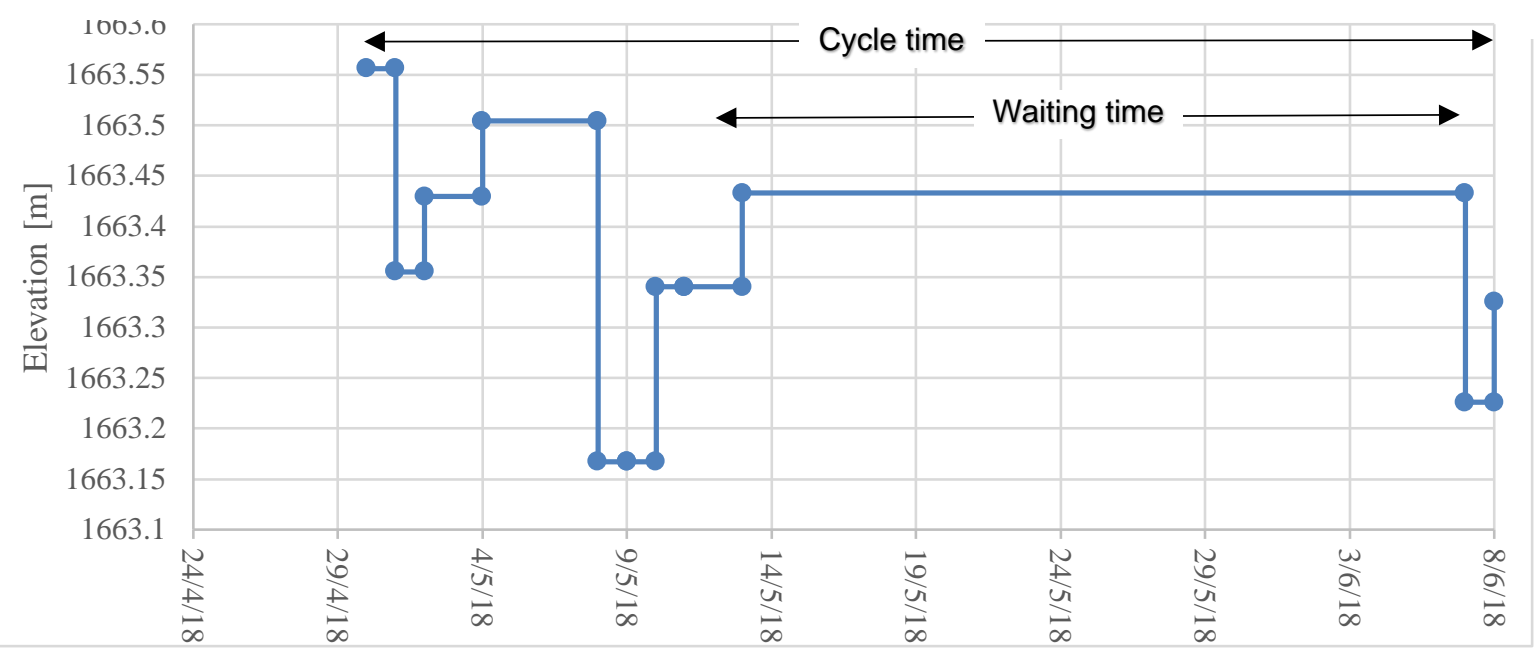

Figure 16: Production graph for a single roadel.

\section{DISCUSSION}

The prototypical management information system developed in this research has shown that the information schema is a sound basis for processing the planning and monitoring inputs to derive the planning and the process flow outputs needed for lean production planning and control of construction products of a continuous rather than a discrete nature. Most importantly, it adds the concept of specific geo-location to the data, thus enabling planning and tracking of products. This distinguishes the planning and flow metrics from the traditional earned-value measure, which is independent of work location. Yet it also raises additional issues and questions that will need to be resolved before commercial systems can be implemented. These concern the exchange of information, the integration of data of continuous products with that of linear or discrete products, development of more sophisticated metrics of process flow, the role of such an information system for overall optimization of flow with autonomous equipment, and the effectiveness of the system as a whole in support of proactive process flow control for road construction projects.

\subsection{Considerations for information exchange}

In the prototype, the schema was implemented simply as a set of relational database tables related to objects in a 3D geometry model (Civil 3D). Since the system was wholly self-contained, no external information exchanges were needed. Commercial systems, however, would need to exchange the model and process information, allowing them, inter alia, to import data from a variety of sources. A good way to achieve this may be through expression of the schema in terms of the IFC schema (BuildingSmart 2013).

Many of the schema's concepts can be expressed in terms of existing IFC entities. IfcElementAssembly A Roadel, for example, represents a part of a product, conforming to the definition of IfcCivilElement, a subtype of IfcElement. A Road Course is used for as-designed description of a road's layered structure and material and can be implemented using IfcMaterialLayerSet in the same way that layers in a concrete slab are defined (note that this does not define the physical geometry of the road, only the nominal thicknesses and material types of its layers). Road Segments, with different boundaries, are aggregations of Roadels, and can be modeled using IfcElementAssembly. Thus, each segment is represented by a set of discrete instances of IfcCivilElements. It is apparent that, since the IFC schema is well developed, concepts that were not conceived of in advance can be implemented using existing information entities. In practical terms, this should be done through the mechanism of a formal Model View Definition. 
However, the risk of abusing the IFC schema arises when doing so. Semantics also have great importance, and entity, relationship and property names should reflect their subjects as precisely as possible. For example, use of an IfcElementAssembly to represent a road course segment is inappropriate, and a new specific entity would be preferable. Similarly, the use of IfcProductDefinitionShape to represent a roadel is a workaround. A definition which allowed the roadels to be aggregated as parts of TIN surface network geometry, as well as triangular prisms, would be more suitable for volumetric computation. In other words, the current IFC Alignment and IFC Roads efforts should consider the specific needs of production and control of infrastructure, with a view to including appropriate entities in future versions of the IFC standard.

\subsection{Linear and discrete project objects}

In reality, infrastructure projects comprise not only discrete and continuous products, as outlined in section 2 , but also have linear products. Linear products, such as longitudinal infrastructure (sewage, drainage and electricity lines, etc.), are managed similarly to continuous products, the only difference being that they have length rather than area or volume. As such, they can be modeled as discrete linear sub-sections of the linear infrastructure. Established lean construction practice and tools are applicable, by default, to buildings with products with discrete locations (Ballard 2000; Kenley and Seppanen 2010). This research is a first step towards production theory development suitable for continuous products, which in practice, should include not only the layered products dealt with explicitly here, but also linear systems. Such hybrid solutions will require further research.

\subsection{Development of Continuous Product Flow Metrics}

Thus far, we have implemented and demonstrated computation and visualization of metrics that are useful for lean construction. The CPPC and the PEI metrics measure the quality of production planning, whereas cycle time, WIP and waiting times measure the quality of production flow. However, these metrics do not provide a complete picture. In addition to the inherent latency of the PDCA cycle, which takes time between measurements and providing information, the flow metrics are difficult to integrate to form a coherent picture of the nature of the flow, nor can it be compared to other projects.

A possible solution is to adapt the Construction Flow Index (CFI) (Sacks et al. 2017) for use in projects with continuous products. The CFI is a composite of flow metrics that is fit to a normalized scale that can be compared across projects. An improved CFI would need to consider effective ways for merging flow properties for continuous, linear and discrete products. Such an index would be essential for road construction projects, but it would also be more effective than the existing CFI or other metrics for building projects, since most buildings contain at least linear products as well as discrete products. Such a development, like the CPPC and the PEI, would need extensive testing and validation in projects with lean production implementations to evaluate their effectiveness and their usefulness.

\subsection{Support for autonomous production planning}

Existing roadwork equipment telemetry systems allow for a high degree of autonomy in executing earthwork operations. However, for optimization of autonomous execution of works on a project scale, the work process flow must also be automated to the fullest degree possible. The proposed information schema can enable autonomous optimization of process sequences using genetic or other optimization algorithms that are driven by utility functions, because the utility functions can now be expressed in terms of process flow metrics. For example, a utility function that included factors like cycle times, WIP and waiting time as well as overall expected remaining project duration and cost, would lead to periodic forward planning that optimized process flow.

\section{CONCLUSION}

The information schema presented maintains the continuous nature of road construction, using discrete elements that can be aggregated dynamically into ad-hoc sub-products (road sections) that are in turn associated with work packages for lean planning. The information classes defined in the schema create a product hierarchy that is continuous, differential and supports aggregation. The concepts of a 'roadel' and of a 'road segment' are its primary new contributions.

Roadels constitute the lowest hierarchical level in the structure of the road and are the building blocks of road segments. Road segments are formed both during production planning and production monitoring. In planning, road segments are defined as aggregations of as-designed roadel slices and are associated with work packages. In monitoring, road segments are emergent aggregations of as-made roadel slices that are constituted whenever progress measurements are made. A Boolean union of road segment instances constitutes the primary product, asdesigned or as-made. 
These new information concepts are specifically designed to support dynamic Lean production planning and control of earthworks operations, including compilation of as-made road sections from the raw data obtained from machine sensors, drones and traditional surveys. The schema enables calculation and visualization of lean metrics of production planning and of process flow, such as the CPPC, PEI, cycle times, waiting times and WIP. As such, it lays the foundation for implementation of tools that support Lean production planning and control for road construction and enable integration and exploitation of the information available from the array of IoT sensors and survey technologies that have become available in recent years.

The schema has been tested using case study data from a large parking lot project, which was modeled with more than 560,000 roadels, and with performance status data collected from 33 working days over a period of two months. Although this is a limited application, in that it covers a short period of time and a small number of synthetically defined work packages, it does illustrate the technical aspects and proves feasibility. The next step in research and development of the concepts should be to test its efficacy through implementation in a prototype software and application to a pilot project.

\section{REFERENCES}

Amann, J., Singer, D., and Borrmann, A. (2015). "Extension of the Upcoming IFC Alignment Standard with Cross Sections for Road Design." 2nd International Conference on Civil and Building Engineering Informatics, Tokyo, Japan.

Ballard, G. (2000). "The Last Planner System of Production Control." PhD Dissertation, The University of Birmingham, Birmingham, U.K.

Björk, B.-C. (1992). “A conceptual model of spaces, space boundaries and enclosing structures.” Automation in Construction, 1(3), 193-214.

BuildingSmart. (2013). "Industry Foundation Classes Release 4 (IFC4)." <http://www.buildingsmarttech.org/ifc/IFC4/final/html/index.htm>.

Deming, W. E. (1986). Out of the Crisis. Massachusetts Institute of Technology Center for Advanced Engineering Study, Cambridge, MA.

Hopp, W. J., and Spearman, M. L. (2011). Factory Physics: Third Edition. Waveland Press.

ISO. (2013). "ISO 16739:2013 Industry Foundation Classes (IFC) for data sharing in the construction and facility management industries." International Standards Organization.

Kenley, R., and Seppanen, O. (2010). Location-Based Management for Construction: Planning, Scheduling and Control. Spon Press, London, UK.

Koskela, L. (2000). "An exploration towards a production theory and its application to construction.” D. Tech, Helsinki University of Technology, Espoo.

"LCI Lean Project Delivery Glossary.” (2017). Lean Construction Institute.

Liebich, T. (2014). “P6 IFC Alignment - Conceptual Model.” BuildingSmart.

Liebich, T., Adachi, Y., Forester, J., Hyvarinen, J., Richter, S., Chipman, T., Weise, M., and Wix, J. (2013). Industry Foundation Classes: Version 4. buildingSMART International.

Rebolj, D., Tibaut, A., Čuš-Babič, N., Magdič, A., and Podbreznik, P. (2008). "Development and Application of a Road Product Model." Automation in Construction, 17(6), 719-728.

Sacks, R., Eastman, C. M., Lee, G., and Teicholz, P. (2018). BIM Handbook: A Guide to Building Information Modeling for Owners, Designers, Engineers, Contractors and Facility Managers. John Wiley and Sons, Hoboken, NJ.

Sacks, R., Seppänen, O., Priven, V., and Savosnick, J. (2017). "Construction flow index: a metric of production flow quality in construction.” Construction Management and Economics, 35(1-2), 45-63.

Schmenner, R. W. (1993). Production/Operations Management: From the Inside Out. Maxwell Macmillan International, New York.

Shewhart, W. A. (1939). Statistical Method from the Viewpoint of Quality Control. Dover, NY.

Shingo, S., and Dillon, A. P. (1989). A Study of the Toyota Production System: From an Industrial Engineering Viewpoint. Productivity Press, Portland, Oregon, USA. 
Sveikauskas, L., Rowe, S., and Mildenberger, J. D. (2018). Measuring Productivity Growth in Construction: Monthly Labor Review. Bureau of Labor Statistics, U.S. Department of Labor.

Vilgertshofer, S., Jubierre, J. R., and Borrmann, A. (2016). "IfcTunnel—a Proposal for a Multi-scale Extension of the IFC Data Model for Shield Tunnels under Consideration of Downward Compatibility Aspects." Proceedings of the 11th European Conference on Product and Process Modelling, CRC Press, Limassol,Cyprus, 175. 